\title{
Use of social media by Emergency Medical Care students and qualified Advanced Life Support providers in South Africa
}

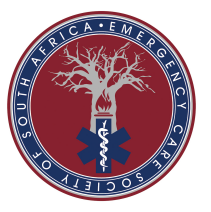

\section{ARTICLE INFORMATION}

Received: 18 September 2019

Revision received: 1 November 2019 Accepted: 7 December 2019

Keywords:

social media

privacy

Emergency Medical Services

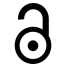

This open access article is distributed under Creative Commons licence CCBY-NC 4.0

\author{
Giehard Hessel, Christopher Stein* \\ Department of Emergency Medical Care, Faculty of Health Sciences, \\ University of Johannesburg
}

*Corresponding author: cstein@uj.ac.za, P O Box 524, Auckland Park, 2006

\section{ABSTRACT}

Background: Social media has emerged as a powerful tool for the dissemination of information across a wide range of health professions, including emergency medical care. While social media platforms can be very effectively used in support of educational and operational information sharing, the ubiquitous presence of smart devices and social media access in the clinical environment has led to concerns about professionals' ethical behaviour; in particular, infringements of patients' privacy rights. This study aimed to explore the use of social media by pre-hospital emergency medical care students and qualified Advanced Life Support (ALS) emergency care personnel.

Methods: A cross-sectional survey was used, with a customdeveloped questionnaire consisting mostly of closed-ended questions, with some confirmatory open-ended questions. The questionnaire was directly administered to emergency medical care students across all four academic years of study at a large urban university in Johannesburg. ALS providers who were members of an email list were also invited to participate in the survey, by completing the same questionnaire online. Data analysis was descriptive in nature.

Results: Response rates were $66 \%$ for students and 10\% for ALS providers. Social media use was reported by almost all participants, with between $78 \%$ and $71 \%$ indicating that they used social media for professional or learning purposes. The majority of ALS providers $(79 \%)$ indicated they were aware of organisational policies on social media use, while only $44 \%$ of students indicated awareness of this, and most (53\%) were unsure. Between $92 \%$ and $73 \%$ of participants stated that they had seen unethical or unprofessional postings on social media. Most participants $(84 \%)$ indicated that they were concerned or very concerned about such postings.

Conclusion: Social media is a powerful tool with both positive and negative outcomes. While its use can facilitate educational interactions and support clinical operations, there are concerns for patients' rights in terms of social media use in the clinical environment - particularly the right to privacy. The development of and compliance with organisational or institutional social media policies may help to enhance the positive aspects of social media use, together with appropriate ethical and professional behaviour.

Hessel G, Stein C. Use of social media by Emergency Medical Care students and qualified Advanced Life Support providers in South Africa . South African Journal of Pre-hospital Emergency Care. 2020; 1(1):9-16. doi:10.24213/1-1-3713 


\section{BACKGROUND}

The advent of social media has revolutionised communication in the modern age enabling the instantaneous dissemination of information to more widespread audiences than previously achieved. While no singular definition exists, social media (SM) can loosely be defined as "Websites and applications that enable users to create and share content or to participate in social networking". ${ }^{1}$ This means individuals can post content online to a public forum and anyone with the same application can access, read, save and share that content. While medicine has been quick to adopt and adapt to changes in technology, advances in social networking are changing the landscape in which medical professionals interact with the public on a daily basis. ${ }^{2}$

These rapid changes to the operational landscape of medical professionals have had unforeseen consequences, resulting in ethical challenges for healthcare professionals and students alike. ${ }^{3} \mathrm{SM}$ has also seen a rise in privacy concerns resulting from the improper use of technology, sharing of too much information and posting of false information. ${ }^{4}$ As a new generation of students enter the healthcare system, it is unclear if these perceived benefits or concerns of SM use will have any effect on their behaviour or ability to learn, compared to older generations.

This study explored the use of SM by pre-hospital emergency medical care (EMC) students and qualified Advanced Life Support (ALS) emergency care personnel.

\section{DESIGN AND METHODS}

\section{Research Design}

This study was a cross-sectional survey of EMC students from a single, large urban university in Johannesburg, as well as a group of qualified ALS emergency care personnel resident across South Africa.

\section{Research Methods}

\section{Study Population and Sample}

This study included convenience samples from two different populations; EMC students from a large, urban university and qualified ALS emergency care providers. The student sample consisted of students across all four academic years of study of a Bachelor of Health Sciences: Emergency Medical Care degree programme. Students were approached directly while on campus during class hours after permission was given by the Head of Department and relevant year co- ordinators. Information about the proposed study was then communicated to each student group (first through fourth year) and a copy of the study information letter was provided. Those students across all four academic years of study who consented to participate comprised the student sample.

The qualified ALS provider sample consisted of individuals subscribed to a privately-owned ALS emailing list, used mainly for the purpose of circulating employment opportunities, Continuing Professional Development (CPD) events, and research participation invitations. Qualifications represented in this mailing list included Critical Care Assistant, National Diploma: Emergency Medical Care and Bachelor of Technology/Health Sciences: Emergency Medical Care, with geographic locations all over South Africa (at least some subscribers in all Provinces).

Subscribers to this mailing list were sent an email invitation to participate, with a link to the survey internet site which contained an information letter (the same as that used for the student sample). Those who consented to participate comprised the ALS provider sample.

\section{The Survey Questionnaire}

The survey questionnaire was developed by the authors specifically for this study as no suitable pre-existing questionnaire could be found. The questionnaire - consisting of 21 questions - had subsections focusing on demographics, the individual's use of SM platforms, posting of media, ethics and SM use, as well as the perceived rationale for SM use. The questions were a mix of closed-ended (binary, multiple choice and Likerttype) and open-ended questions. Open-ended questions were used to capture very fundamental factual data or more detailed responses based on a prior closed-ended question. For example, in some cases if participants chose a specific binary response (yes/no) they were prompted to give the most important reason for their response. The questionnaire was subjected to a basic assessment of face validity by the authors prior to release.

The questionnaire had a conditional branching design, as not all questions were intended for participants from both populations and some were conditional, based on responses to earlier questions. The questionnaire was anonymous as no identifying information was requested from participants.

\section{Questionnaire Distribution and Data Collection}

Methods of questionnaire distribution differed between the two study populations. For the stu- 
dent population, questionnaires were distributed in hard copy and responses were recorded on the questionnaires, which were collected by one of the authors immediately after completion. Prior to this, information about the research was also provided to students in hard copy, and each student who agreed to participate signed an informed consent form. Consent forms and questionnaires were collected separately.

For the ALS provider population, an invitation email was sent to all subscribers of a South African ALS emailing list as described above. The invitation email was sent to the mailing list owner, who then sent it to subscribers. The invitation email contained a hyperlink to the survey internet site, which was designed and implemented using Google ${ }^{\circledR}$ Forms. The opening page of the survey site contained information about the survey, identical to that provided to the student population in hard copy. After this information, at the bottom of the page, a checkbox was presented to prospective participants and they were requested to affirm their consent to participate using the checkbox. Only those who did so were permitted to continue to the questionnaire itself. Questionnaire responses were automatically written to an online spreadsheet application and downloaded at the end of the survey for analysis.

For the student population, data collection spanned a period of roughly two weeks during which contact was made with students of each academic year for the procedure described above. For the ALS provider population, the survey remained open for a period of four weeks; two reminder emails were sent during this time.

\section{Data Analysis}

Data from closed questions were analysed descriptively by calculation of mean and standard deviation, category frequencies and percentages, as applicable. Data from open-ended questions were analysed by the identification and extraction of commonly occurring keywords or phrases. Statistical analysis was done using IBM SPSS (version 25.0, IBM Corporation, New York).

\section{Ethical and Other Approvals}

Prior to data collection, institutional approval was obtained from all relevant University authorities. Ethical clearance was granted from the University's Faculty of Health Sciences Research Ethics Committee, with clearance REC-01-37-2017.

\section{RESULTS}

\section{Response Rate}

A total of 73 students across all four academic years of study completed the questionnaire. This comprised $66 \%$ of the total student cohort of 108 . A total of 50 ALS providers responded to the email survey invitation and completed the questionnaire online. This was roughly $10 \%$ of the total estimated number of ALS providers subscribed to the mailing list at the time (480 subscribers). Participant demographics are shown in Table 1.

Table 1: Demography of Social Media Use

\begin{tabular}{lll}
\hline Gender $^{a}$ & Students $\mathbf{n}(\%)$ & ALS Providers n (\%) \\
\hline Male & $43(59)$ & $32(65)$ \\
Female & $30(41)$ & $17(35)$ \\
\hline Academic Year of Study & Students n (\%) & ALS Providers n (\%) \\
\hline First Year & $23(32)$ & - \\
Second Year & $17(23)$ & - \\
Third Year & $18(25)$ & - \\
Fourth Year & $15(21)$ & - \\
\hline Qualification & Students $\mathbf{n}(\%)$ & ALS Providers $\mathbf{n}(\%)$ \\
\hline Bachelor's Degree & - & $38(76)$ \\
Critical Care Assistant & - & $10(20)$ \\
National Diploma & - & $2(4)$ \\
\hline Age (years) & & ALS Providers mean (SD) \\
\hline - & Students mean (SD) & $32.5(7.6)$ \\
\hline
\end{tabular}

$\mathrm{SD}=$ Standard deviation, $\mathrm{a}=$ one respondent did not give their gender, $\mathrm{b}=$ four respondents did not give their age 


\section{Characteristics of Social Media Use}

One hundred and seventeen (95\%) respondents indicated they had at least one SM account. Among ALS providers there was a total of $44(88 \%)$ who had at least one SM account, with an average num- ber of $6.1( \pm 2.3)$ accounts per respondent. Of the student cohort, $73(100 \%)$ indicated that they had at least one SM account, with an average of 5.8 $( \pm 2.6)$ accounts. The most common forms of SM across all respondents were WhatsApp, Facebook, Instagram, YouTube, Skype, and Twitter (Table 2).

Table 2: Most Common Forms of Social Media: All Respondents

\begin{tabular}{ll}
\hline Type of Social Media & All Respondents $\mathbf{n}(\%)$ \\
\hline WhatsApp & $117(100)$ \\
Facebook & $112(96)$ \\
Instagram & $87(74)$ \\
YouTube & $68(58)$ \\
Skype & $57(49)$ \\
Twitter & $57(49)$ \\
\hline
\end{tabular}

The most prevalent general reason for using SM across all respondents was "Ease of Communication" ( $\mathrm{n}=97 ; 83 \%)$, followed by "Staying in Contact with Friends/Family" (n=96; 82\%) and "Instant Messaging" ( $\mathrm{n}=85 ; 73 \%)$. Of all respondents, $34(29 \%)$ indicated using SM for "Professional Development" with $53(45 \%)$ using SM for "Reduced costs". Only six $(4 \%)$ respondents cited SM uses that were not among the standardised categories for the purposes of this research.

\section{Professional Use of Social Media}

A total of $91(78 \%)$ respondents indicated that they were on SM groups for professional or learningrelated reasons. Of ALS providers who indicated they had SM, 39 (89\%) stated that they use SM professionally or in a work-related capacity, with
$11(30 \%)$ indicating SM use being compulsory for their operational duties. Of the student cohort, $52(71 \%)$ indicated using SM for learning-related reasons, with seven (14\%) stating that its use was compulsory for this purpose. WhatsApp, Facebook and Twitter were consistently the most common platforms used for professional or learningrelated reasons.

Of the 91 respondents indicating that they use SM professionally or for learning-related reasons, four respondents did not answer the follow-up question requesting more detailed descriptions of this type of SM use. Of the remaining 87 respondents, the largest group indicated that they use SM for "Staying up to date with the latest clinical information/literature" (Table 3)

Table 3: Main Reason for Using Social Media Groups: All Respondents

\begin{tabular}{ll}
\hline Reason & All Respondents n (\%) \\
\hline Staying up to date with the latest clinical information/literature & $47(54)$ \\
Communicating or discussing emergency incidents with colleagues & $38(44)$ \\
Sharing other work-related information & $38(44)$ \\
Discussing clinical information/asking or advice about clinical care & $17(20)$ \\
Non-work-related communication & $14(16)$ \\
\hline
\end{tabular}

\section{Social Media Policies}

When asked if their learning institution had an SM policy, 32 (44\%) of students answered "yes", two $(3 \%)$ answered "no", and $39(53 \%)$ were "unsure". Students who indicated that their institution does have an SM policy were asked if they received training on their institution's SM policies and how helpful this training was. Eight $(25 \%)$ students indicated they received training on SM policies, with six $(75 \%)$ indicating this training was somewhat or very helpful. Two (25\%) of the students indicated that this training was neither helpful nor unhelpful. Among students who indicated that their institution did not have an SM policy or were unsure, $40(66 \%)$ stated they were willing to receive training, while 21 (34\%) were not willing to receive any training.

ALS providers were also asked if their workplace had a SM policy; $34(79 \%)$ answered "yes", five 
(12\%) answered "no", and four (9\%) were "unsure". ALS providers who indicated that their employer did have an SM policy were also asked if they received training on the SM policy, of which $13(34 \%)$ indicated that they had received training. Of these, $11(85 \%)$ found the training somewhat or very helpful, and two $(15 \%)$ indicated that the training was neither helpful nor unhelpful. Of the ALS providers who indicated that their companies did not have an SM policy or were unsure, four $(100 \%)$ indicated they were willing to receive train- ing.

\section{Social Media Ethics}

Of all respondents, 99 (81\%) indicated that they had seen unethical or unprofessional media postings of a clinical nature on SM platforms, and 68 $(56 \%)$ indicated that they were aware of one or more persons being reprimanded for SM postings within the preceding two years. A detailed breakdown of these responses, per category of respondent, is shown in Table 4.

Table 4: Experience of Unethical or Unprofessional Social Media Use

\begin{tabular}{llll}
\hline Group & Experience & Yes n (\%) & No n (\%) \\
\hline Students & $\begin{array}{l}\text { Have you seen unethical or unprofessional postings on so- } \\
\text { cial media? }\end{array}$ & $53(73)$ & $20(27)$ \\
& $\begin{array}{l}\text { Are you aware of one or more persons being reprimanded } \\
\text { for social media postings in the last two years? }\end{array}$ & $31(43)$ & $41(57)$ \\
ALS & $\begin{array}{l}\text { Have you seen unethical or unprofessional postings on so- } \\
\text { cial media? }\end{array}$ & $46(92)$ & $4(8)$ \\
& $\begin{array}{l}\text { Are you aware of one or more persons being reprimanded } \\
\text { for social media postings in the last two years? }\end{array}$ & $37(74)$ & $13(26)$ \\
\hline
\end{tabular}

In addition to the responses above, respondents were asked to give examples of what they believed to be unethical or unprofessional SM use. These examples were categorised and are shown in Table 5 below.

Table 5: Categories of Unethical SM Activity Experienced by Respondents

\begin{tabular}{ll}
\hline Category & All Respondents n (\%) \\
\hline $\begin{array}{l}\text { Any media depicting patients or their injuries without consent } \\
\text { Any media depicting confidential or identifying patient information in- }\end{array}$ & $35(59)$ \\
cluding patient descriptions without consent & \\
$\begin{array}{l}\text { Any media depicting deceased patients and/or body parts of patients } \\
\text { without consent }\end{array}$ & $8(8)$ \\
$\begin{array}{l}\text { Any media or comments depicting EMS crews or patient treatment } \\
\text { without consent }\end{array}$ & $14(14)$ \\
\hline
\end{tabular}

More than half of the respondents reported having seen SM postings that depicted patients or their injuries. There was a lesser prevalence of graphic postings depicting deceased patients and EMS personnel or instances of patient treatment. By definition, the former types of SM postings occurred without patient consent. Slightly more than a third of respondents reported seeing SM posts that included confidential clinical information, or information that could have identified individual patients.

Finally, when asked about their level of concern regarding unethical or unprofessional media postings on SM platforms, 51 (42\%) respondents in- dicated "Very Concerned", 52 (42\%) indicated "Concerned", 17 (14\%) indicated "Neutral", two (2\%) indicated "Not Concerned"). Among ALS providers, $44(88 \%)$ indicated being either "Very Concerned" or "Concerned" compared to 60 (82\%) among students. Six ALS providers (12\%) were either "Neutral" or "Not Concerned" compared to $13(18 \%)$ students.

\section{DISCUSSION}

With the widespread use of SM platforms in today's society, it is inevitable that questions will be raised about its ethical use across a variety of fields and its ability to maintain or protect privacy and 
confidentiality. In 2017, South Africa alone had more than 16 million Facebook users, representing approximately $30 \%$ of the country's population $^{5}$ with a significant proportion of these users being medical professionals or students. All medical professionals and students are obligated by law to protect a patient's privacy and confidentiality. ${ }^{6,7}$ In this online survey, we aimed to explore SM use by EMC students from one University and qualified ALS providers.

\section{Response Rate, Demographics and Character- istics of Social Media Use}

The survey response rate was notably higher for students $(73 / 108,66 \%)$ than it was for ALS providers $(50 / 480,10 \%)$. This was most likely due to the method of administration, with students being approached to participate after classes and having the survey questionnaire administered directly in hard copy. ALS providers, on the other hand, were invited to participate by email - an approach that is expected to elicit a lower response rate compared to direct administration.

The student cohort was approximately 10 years younger than the ALS provider cohort, with a roughly equal distribution across gender categories in both. The student cohort was fairly evenly distributed across academic years of study (first - fourth), while for the ALS provider cohort, there were roughly four times as many degree providers as others (Table 2). Virtually all respondents indicated that they had at least one SM account, with the prevalence of SM accounts higher in the student cohort (100\%) than in the ALS provider cohort $(88 \%)$. The average number of SM accounts per respondent was very similar between the student and ALS provider cohorts (5.8 vs. 6.1) (Table 3).

\section{Social Media Policies}

Social media policy may play a key role in delineating acceptable and unacceptable SM behaviour both in the workplace and at higher education institutions. Despite this, available data suggest that few of these organisations have clear and easily accessible SM policies. ${ }^{8,9}$ Furthermore, an international study of SM in health sciences found that there was little instruction in the mainstream education of health sciences students on how to securely and appropriately engage with digital media, and this was echoed in the present study. ${ }^{10}$ Roughly half of the students in the current study indicated that they were unsure, while $44 \%$ indicated that they knew of an institutional SM policy. This was very different in the ALS provider cohort, where $79 \%$ of respondents indicated that they knew of an organisational SM policy. The greater knowledge of SM policy among operational ALS may be explained by greater emphasis placed on this by employers in an effort to avoid SM-related liability, while this aspect may be seen as less of a risk at higher education institutions.

\section{Professional and Educational Use of Social Me- dia}

The role of SM in disseminating both learning material and work-related information is obvious from the responses in Table 4. For ALS providers, SM has become an efficient way of sharing work-related information. Almost a third of ALS providers indicated that SM use was compulsory for operational duties. The majority of students also indicated that SM was used, at least to some extent, for the dissemination of learning material, although it is unclear whether this is openaccess material (e.g. Free Open Access Medical Education - FOAMed) or material from the institution they were attending. A small minority of students indicated that SM use was compulsory for learning activities.

While available literature suggests substantial uptake of SM for professional development among emergency physicians, $^{11,12}$ relatively little peerreviewed comparative data are available about professional and educational social media use among pre-hospital emergency care workers. One survey conducted in the United States suggests that pre-hospital emergency care workers do not readily participate in FOAMed SM activities, with a maximum $31 \%$ of respondents having accessed FOAM SM resources. ${ }^{13}$ When items one and four in Table 4, which both relate to educational development, are combined, 55\% (64) of respondents in the current study indicated that their primary use of SM is of an educational nature.

\section{Social Media Ethics: Privacy and Confidential- ity}

In the group of surveyed respondents, experience of unethical or unprofessional SM postings related to privacy and confidentiality was common. This was true among both the student and ALS provider groups, with a slightly higher prevalence of such experience in the ALS provider group (Table 5). Examples of unprofessional content included patient injuries and treatments clearly visible in photographs, graphic pictures of deceased patients, graphic images of body parts, and the distribution of photos of motor vehicle accident scenes where patients' identifying information was clearly visible etc. (Table 6). Of the students who indicated that they had seen unethi- 
cal or unprofessional media, the majority indicated that they were either very concerned or concerned about the unethical and unprofessional postings.

Unfortunately, the above results are not isolated and number of international studies have identified similar, or even worse, SM conduct among healthcare students and clinicians across a range of disciplines. ${ }^{10,14-17}$ Many of these studies describe a broad range of behaviours which are usually aggregated under the term 'unprofessional'; however, all of them identified SM activities that breach patient rights to privacy as identified in the current study.

\section{CONCLUSION}

In this study on SM use by EMC students and qualified ALS providers, the widespread use of various SM platforms for work and learning-related activities was observed. Responses further suggested that ALS providers were mostly aware of SM policies in their organisations, while students were mostly unsure whether there were institutional policies on their use of SM. Of some concern is the high prevalence of self-reported instances of SM use that conflicted with students' and ALS providers' duty to protect the privacy of patients. The majority of respondents indicated that this made them concerned or very concerned.

The use of SM in EMC can clearly be both positive and negative. SM is a very powerful medium for low cost and efficient dissemination of clinical and other information. It is already in use worldwide as a platform for open access to many helpful EMC educational resources. However, SM also has the potential to pose a serious threat to a range of patient rights, particularly privacy, if it is used inappropriately. All EMC provider organisations and educational institutions should create and implement a policy on SM use, based on recommendations such as those published by Grobler and Dhai, ${ }^{18}$ and should ensure that both students and providers are trained in and adhere to them.

\section{CONFLICTS OF INTEREST}

The authors report no conflicts of interest.

\section{AUTHOR CONTRIBUTIONS}

$\mathrm{GH}$ conceived the study, collected data, analysed data, contributed to drafting of the manuscript and approved the final version of the manuscript. CS analysed data, contributed to drafting of the manuscript and approved the final version of the manuscript.

\section{REFERENCES}

1. Social media. The Oxford English Dictionary. Oxford University Press, 2017.

2. Hendry R. Practicing in the Facebook age. Medical Protection Society Casebook 2013;21:4.

3. Chretien KC, Greysen SR, Chretien J, T TK. Online posting of unprofessional content by medical students. JAMA 2009;302:1309-15.

4. O'Keeffe GS, Clarke-Pearson K, Council on Communications and Media. The impact of social media on children, adolescents, and families. Pediatrics 2011;127:800-4.

5. How many people use Facebook, Twitter and Instagram in South Africa. Businesstech, 2017. (https: / / businesstech.co.za/ news / internet / 199318 / how - many people-use-facebook-twitter-andinstagram-in-south-africa/) (visited on 06/30/2018).

6. Confidentiality-protecting and providing information. booklet 5. Pretoria: Health Professions Council of South Africa, 2016. (https: / / www . hpcsa . co . za / Uploads / Professional _ Practice / Conduct \% $20 \div 26 \% 20 \mathrm{Ethics} /$ Booklet $\% 205 \%$ 20 Confidentiality $\% 20$ protecting 20 and $\% 20$ Providing $\% 20$ Information 20. September $\% 202016$. pdf) (visited on 01/20/2019).

7. South Africa. Protection of Personal Information Act No 4 of 2013.

8. Pomerantz J, Hank C, Sugimoto CR. The state of social media policies in higher education. PLoS One 2015;10:1-17.

9. Kind T, Genrich G, Sodhi A, Chretien KC. Social media policies at US medical schools. Med Educ Online 2010;15:5324.

10. O'Sullivan E, Cutts E, Kavikondala S, et al. Social media in health science education: An international survey. JMIR Med Educ. 2017;3:e1.

11. Cadogan $\mathrm{M}$, Thoma B, Chan $\mathrm{T}$, Lin $\mathrm{M}$. Free Open Access Meducation (foam): The rise of emergency medicine and critical care blogs and podcasts (2002-2013). Emerg Med J. 2014,31:401-4.

12. Neill A, Cronin J, Brannigan D, O'Sullivan R, Cadogan $\mathrm{M}$. The impact of social media on a major international emergency medicine conference. Emerg Med J. 2018;26:79.

13. Bucher J, Donovan C, McCoy J. EMS providers do not use FOAM for education. Int J Emerg Med. 2018;11:27. 
14. Chretien KC, Tuck M. Online professionalism: A synthetic review. Int Rev Psychiatry 2015;27:106-17.

15. Greysen SR, Chretien KC, Kind T, Young A, Gross CP. Physician violations of online professionalism and disciplinary actions: A national survey of state medical boards. JAMA 2012;307:1141-2.

16. Langenfeld SJ, Cook G, Luers CST, Schenarts PJ. An assessment of unprofessional behav- ior among surgical residents on Facebook: A warning of the dangers of social media. J Surg Educ. 2014;71:e28-32.

17. Steele S, Adcock C, Steele A. Ethical, legal and professional issues arising from social media coverage by UK Helicopter Emergency Medical Services. Emerg Med J. 2016;33:57-60.

18. Grobler C, Dhai A. Social media in the healthcare context: Ethical challenges and recommendations. S Afr J Bioeth Law 2016;9:22-5. 